\title{
Adaptive Psychopathy: Empathy and Psychopathy are Not Mutually Exclusive
}

\author{
Stephen Mihailides ${ }^{*}$, Roslyn Galligan and Glen Bates
}

Department of Psychological Sciences, Swinburne University, Australia

"Corresponding Author: Stephen Mihailides, Department of Psychological Sciences, Swinburne University, Australia, Tel: +61 392148000 ;

E-mail: smihailides@swin.edu.au

Received date: August 15, 2017, Accepted date: August 22, 2017, Published date: August 29, 2017

Copyright: (C) 2017 Mihailides S, et al. This is an open-access article distributed under the terms of the Creative Commons Attribution License, which permits unrestricted use, distribution, and reproduction in any medium, provided the original author and source are credited.

\begin{abstract}
This work tests one assumption of the Adaptive Psychopathy hypothesis, namely that empathy and psychopathy are not mutually exclusive for normal-range psychopathy. In earlier work, a Directional Vector was operationalized, testing the core assumption of new theory. Experimental participants were 34 university students studying psychology ( $38 \%$ were male, $M=22.08, S D=2.53$ years and $62 \%$ were female, $M=25.33$ years, $S D=8.33$ ) who were presented with an ideographic nomothetic scenario designed to rouse a survival threat. This exposure elicited elevations in participants' state psychopathy levels, for targets (termed moral deviants) with no change in psychopathy levels for the control group. Hypothesis testing using the Moral Inversion Method, confirmed the retention of empathy for individuals, outside the quarantined zone, not affected by moral inversion. Consistent with hypotheses, empathy was sacrificed for quarantined moral deviant targets, and elevations in state psychopathy emerged, directionally, for moral deviants. Findings of the current research are summarized with the new theoretical term, the Directional Empathy hypothesis.
\end{abstract}

This work extends findings of prior research by testing the theoretical tenet that empathy and psychopathy are not mutually exclusive for normal-range psychopathy. It furthers prior work that formulated the foundations of two heuristics termed the Adaptive Psychopathy Hypothesis, and its theoretical basis for the State-Psychopathy Hypothesis. Both terms deploy the Moral Inversion Method to derive empirical support in tests of the assumptions of new theory about psychopathy and its posited adaptive basis.

Mihailides et al. established the basis of the State Psychopathy Hypothesis. Earlier work references the Directional Vector hypothesis, which tested the mechanistic features of new theory, and the basis upon which to elicit elevations in psychopathy levels for normal populations. A selective review of the empathy literature follows, which precedes the adaptation of new theory, in order to test the relationship between empathy and psychopathy expression for people with normal-range psychopathy. The experimental work extends the Directional Vector hypothesis, by defining empathy levels for targets both inside and outside the quarantined zone of the psychopathic modular mind.

Keywords: State Trait Psychopathy; Directional Vector; Quarantine Zone; Adaptive Psychopathy; Empathy

\section{The Adaptive Psychopathy Hypothesis}

Mihailides et al. [1] have recently argued and demonstrated that affect from the psychopathic spectrum, namely the instinct to slay, cold heartedness, baseness, cruelty, pleasure at suffering and ghoulish humor has directional expression. Directionality, according to this theorizing, means that the psychopathic affect has a bounded, quarantined expression, affecting a limited range of targets. Such directionality extends to encompass consideration of how other related aspects of human functioning which fall outside this quarantined zone, for example empathy, might be affected when the human territorial, survival instinct is aroused.

Mihailides et al. [1] manipulated territorial threat under experimental conditions, rousing the survival instinct, inducing elevations in psychopathy in participants, for maligned outsiders, termed moral deviants in the Moral Inversion Method. The Moral Inversion Method is a combined idiographic-nomothetic method, using audiovisual vignette induction to elicit elevations in state psychopathy, directionally. Moral deviants are imaginary maligned others, who are defined within the idiographic component of the method to hold a moral outlook strongly opposed to that of the judgers. Socio-emotional, socio-sexual, and socio-political conflicts with those of judgers are embedded in the vignettes of morally deviant ideologies.

The Directional Vector hypothesis of experimental work subsumes theoretical terms in a methodology for orienting the survival instinct towards a territorial incursion. As argued by Mihailides et al. [1] this new theorizing is grounded in evolutionary psychology where psychopathic cognition was likened to the output of a targeting scanner that sweeps socio-cultural landscapes, in order to identify threat. New theory posits that psychopathic cognition is roused wherever an appraiser experiences socio-emotional, sociocultural, socio-sexual and socio-spiritual conflicts, of a directional nature, targeting subpopulations. Within evolutionary theory, psychopathic cognition is construed as a sexually selected, human adaptation. Theory posits that a psychopathic modular mind operates on particular cognitive input, stripping it of affect from the empathic 
spectrum. The assumption of modeling is that associated psychopathic cognition is relatively quarantined from other cognitive activities.

Importantly, this theory predicts that the functions of the psychopathic modular mind should operate concurrently with those of ordinary cognitive functions. A central prediction posits that psychopathic and empathic cognition are not mutually exclusive. Theory predicts that empathic facility is sustained, directionally, for individuals not bounded by the quarantined vector of psychopathic cognition. This work tests the assumptions of this aspect of the theory.

\section{Features of Empathy and Psychopathy in Human Populations}

Empathy is generally recognized as a valued human capacity, prevalent in all human populations [2]. However, there is lack of consensus about details of individual-differences formulations in how they define cognitive structures and processes thought to be implicated in empathic facility [3-5]. The understanding of empathy has expanded, drawing a distinction between, for example, cognitive and affective empathy in the general literature, with adaptation of this, as it pertains to psychopathy [6,7]. Formulations can vary in the style or manner in which they outline relationships between cognitive, affective and behavioral expression of empathy. A multi-disciplinary science has defined some of the relationships between, for example, the expression of empathy and child-rearing practices [8], and tolerance for alien cultures [9]. Empathy also has a role in caring behavior, and pro-social orientation in restorative justice anti-bullying practices [10]. Within forensic psychology one focus has been examination of the capacity for empathy-or its opposite-that is, lack of empathy, and expected relationships to recidivism, and responsiveness during intervention for offence specific treatment foci [11]. A literature also exists that seeks to define different kinds of empathy pathology, such as those that might be expressed in autism spectrum conditions [12], anti-social and psychopathic populations [13].

Generally, the psychopathy literature views absence of empathy as synonymous with presence of psychopathy [14]. Psychopathy, construed as a condition of pathology, is implicated with compromised capacity for empathy, or lack of empathy. Lack of empathy is traced by the Hare [14] Psychopathy Checklist-Revised (PCL-R) measure of psychopathy to the interpersonal/affective factor of Hare's two-factor, four-facet model. Similarly, lack of empathy has obvious expected inverse correlations to Lilienfeld's and Andrew's [15] Cold Heartedness factor on the Psychopathic Personality Inventory (PPIR), or to the Meanness factor of the Triarchic Psychopathy Measure [16].

However, for the psychopathy literature, no matter whether the focus is on conditionability or socialisation and their effects upon lack of empathy or moral process, there is an assumption of deficit made by that literature, without sufficient scrutiny of exactly how deficient, or in what contexts the deficit is expressed [6,7,17-21]. Despite an overall position in the literature about apparent empathy deficits for psychopathic populations, work, for example, by Lishner et al. [7] note curious findings in that little association was found between affective empathy and psychopathy levels. Where authors found an association, contrary to what might be expected, a higher association was observed between affective empathy and psychopathy for non-forensic samples. Other work by Marsh and Cardinale [22], described specific deficits in ability to appraise or recognise states of fear in others, but not global deficits of empathy in people with high levels of psychopathy. These findings highlight exceptions to understanding of the complex, multi- faceted structure of the empathy construct, warning of dangers of reductionist statements about empathy in relation to psychopathy [23].

There remain further and separate questions about empathy such as whether or not there are specific, exceptional conditions where empathic functioning can remain intact even for those high in psychopathy. Such a view might posit that residual empathy is reserved, for example, in its expression for a much smaller group of the psychopathic person's family, allies or inner circle. The same analysis can be applied to ideas about a potential for domain specificity and amoral behaviour where its' opposite-appropriate moral behaviourexists for a particular narrow domain. Then, if arguments are extended by giving consideration to populations with normal-range psychopathy, we assume empathic facility is relatively intact for the majority of those from the general population. However, by contrast we know very little about the relationship of normal psychopathy levels to normal levels of empathy [24].

Given new terminology of the Adaptive-Psychopathy Hypothesis [1] where a vector of directionality occurs for quarantined zones of cognition laden with affect from the psychopathic spectrum, equally, for non-affected areas a vector of directionality of retained empathy function is implied. If survival instinct underpins the activities of the psychopathic targeting scanner, then equally, activities of the empathic facility are implicated in survival as well. Presumably, enhanced survival potential should occur when directional empathy conjoins the person to known allies. This work posits that psychopathy adds a second conjoin to one's allies, where there is shared overlap between people holding commonly quarantined vectors targeting common alien others, and induced by survival threat. Stated another way, empathy and psychopathy at normal levels create double conjoins between one's self and allies.

Thus, psychopathic cognition need not imply separation and divergence from a collective. Quite the contrary, collective psychopathy should represent group or social trending where common allies also mean empathy for common allies to destroy common threats. Here then, is the empathy conjoin which can be expressed as affective empathy for friends, yet suspension of empathy for common enemies. Overlapping quarantine zones shared by people or groups higher in psychopathy and lower in empathy-implies a capacity for conjoins even for such groups. Said another way, psychopaths sharing ideologies targeting their perceived common enemies have potential to align. However, contrary to the two separate psychopathy literatures that never view empathy and psychopathy as co-occurring, the Adaptive Psychopathy Hypothesis sees them as conjoined. The Adaptive Psychopathy Hypothesis is thus, a bridging heuristic that expects that the psychopathy and empathy literatures are naturally conjoined in one important new way. There is no expectation that elevations in empathy must imply absence of psychopathic cognition and vice versa. Yet, instead, there are expected cognitive orientations where a person may transition from warm-heartedness of the empathic spectrum of affect, to the cold-heartedness of the psychopathic spectrum of affect, depending upon whom the person focuses their thinking. According to Mihailides et al. [1], territorial survival threat, induced by judgers' attention upon seriously opposed socio-affective, sociocultural, sociosexual or socio-spiritual sectors, elicits elevations in state psychopathy. The higher the degree of survival threat elicited by territorial incursion, the greater the transition expected to the psychopathic spectrum of affect. During such transitions, cold heartedness, baseness, meanness, even greed for resources, together with potential for contextual disinhibition is expected to occur. Violation of moral codes and social 
Page 3 of 6

norms is expected in association with survival threat as a means to justify base, violent, and even deadly acts. Therefore, a directional vector for empathy (or its lack), as well as for disinhibition, is also predicted during transitions into psychopathic cognition.

\begin{abstract}
Aims
This work extends that of Mihailides et al. [1], and seeks to demonstrate that empathic processing is retained, but directionally, whilst eliciting elevations of state psychopathy simultaneously. Elevations in state psychopathy are predicted in response to moral deviants (a term from the Moral Inversion Method) who represent a survival threat to participants. The work tests a core tenet of new theory, that being that empathy and psychopathy are not mutually exclusive. It is expected that empathic capacity will be retained for those targets not bounded by the person's targeting scanner (where their quarantined psychopathic cognition occurs). At the same time, lack of empathy should emerge from an appraiser whose cognition is focused upon a target within the quarantined psychopathic vector. Stated another way the current study tests the tenet that collective psychopathy emerges trans-culturally, and does so when collectives experience territorial incursion, as a survival threat. This study tests the tenet that psychopathic cognition targets people, situations, contexts, cultures, spiritualties, sexualities, laws, and social norms, alien to one's own, and yet where empathic process is preserved for non-alien others.
\end{abstract}

\section{Hypotheses}

To test these new tenets, participants' empathy levels were measured for two distinct groups. Under conditions of psychopathy induction, elicited by a survival threat and attributed to a territorial incursion by morally deviant outsiders, it was hypothesized that empathy levels would diminish significantly only for moral deviants (H1). Concurrently, loss of empathy was not expected from participants towards their close loved ones. A concurrent empathy test was conceived, as a measure of relative empathy levels from participants towards three distinct groups. It was anticipated that a person's empathy for people they consider their close loved ones, should be higher than their general empathy for members of the community (H2). By way of relative contrast, a person's general empathy for members of their community was expected to be higher than their empathy for morally deviant outsiders (H3), who represent the survival threat. Thus, a three-tiered level of empathy was predicted by hypotheses.

\section{Method}

\section{Study 1}

Participants: Participant inclusion criteria were adults with normal levels of psychopathy. Participants were 68 people, 34 of whom were students from the Department of Psychological Sciences at Swinburne University ( $38 \%$ were male, $\mathrm{M}=22.08$ years, $\mathrm{SD}=2.53$ years and $62 \%$ were female, $\mathrm{M}=25.33$ years, $\mathrm{SD}=8.33$ years). Thirty four of the 68 participants were adults from a local community radio station $(35 \%$ were male, $\mathrm{M}=29.33$ years, $\mathrm{SD}=8.27$ years, and $65 \%$ were female, $\mathrm{M}=29.18$ years, $\mathrm{SD}=6.10$ years). One case was suspended from the test group for experimental analyses due to incomplete data.

Materials: Participants were subjected to psychopathy induction of the Moral Inversion Method, as described in Mihailides et al. [1]. Therefore, prior to psychopathy induction, participants' idiographic data for their moral choice attributes were generated, as described in Mihailides et al. [1]:

The Idiographic Component of Research: Generating Participants' Moral Choice Attributes

During Session 1, participants were asked to classify their most morally unacceptable terms from seven pull-down menus. The pulldown menus contained forced-choice items and participant were required to select the item that represented the most immoral term for each pull-down menu. The categories for the pull-down menus were as follows:

\section{1. $<$ Immoral political ideology $>$ : e.g. fascist}

2. $<$ Immoral sexual/romantic practice $>$ : e.g. bisexual marriage

3. $<$ Immoral sexual recreation $>$ : e.g. group sex

4. $<$ Immoral method of handling $>$ : e.g. abduction

5. <Immoral punishment>: e.g. enslaving

6. $<$ Immoral rewards $>$ : e.g. money

7. $<$ Profession most immoral when misused $>$ : e.g. police

Participants' choices were their Moral Choice Attributes from Session 1, which were reserved for utilization in the psychopathy induction during Session 2.

Baseline measures: During Session 1, Participants were given the Triarchic Personality Measure. The Triarchic Personality Measure is a 59 item measure comprising three subscales termed Boldness (e.g. I am well-equipped to deal with stress), Meanness (e.g. How other people feel is important to me R) and Disinhibition (e.g. I often act on immediate needs). Items are measured on a 5-point Likert-Type scale where $1=$ not at all like me and $5=$ very much like me. Items were modified to be in the present tense so changes could be assessed from pre to post manipulation of territorial survival threat. During session 1, participants were also given a measure of empathy, the Toronto Empathy Questionnaire, a 16 item scale (e.g. When I see someone being treated unfairly, I do not feel very much pity for them). Items are ordinarily measured on a 5-point Likert-Type Scale where ' 0 '=Rarely and ' 4 '=Always. Participants were asked to respond to each item, twice, for two response contexts. One response context was for "my close people" and the second was for "members of the community".

\section{Procedure: Psychopathy Induction: The 'Moral Inversion' Induction}

A vignette was pre-recorded and administered in the oral mode, by headset, together with imagery presented by computer in a slide show of the Holocaust, of Abu Ghraib, the Cambodian genocide and the Brixton Riots. The slide show had subtitles such as "Emergency Broadcast" and "State of Emergency" interspersed between imagery. The participant's name was administered during the oral in order to personalise a message to them. The vignette reads as follows:

Jenny, your society has a new social mandate that embraces a new social order. They have adopted a <Immoral Political> ideology. They and their millions of supporters have subverted power, taken control of the country's financial machinery, secured military assets and they have a tight hold of control over the country. Society's new laws esteem <Immoral Romantic Practice> in a new mode of relationships. They value <Immoral Recreational Activity> as a social recreation. International commentators have named members of this new society moral deviants. They also have new laws making it a criminal offence to live by society's old laws. As Such, what moral deviants term a 'social 
Page 4 of 6

dissident' is anyone of the old world order. People of the old order are considered Enemies of the State. <Immoral Method of Handling > may be freely used by a moral deviant against anyone who is an Enemy of the State in order apprehend them. A moral deviant who hands over an Enemy of the State to authorities is guaranteed an <Immoral Reward>. Once detected, Enemies of the State are forcibly subjected to a reality $T V$ conversion process. If they do not convert and openly become a moral deviant, they are punished under new moral deviant laws and are <Immoral Punishment>. Once converted, a new social deviant must prove their fidelity to the State and its new laws, by six months service as a volunteer to the <Immorally used Vocation>. You are caught in this new social revolution, surrounded by it, and are trying to decide what your choices are, and if you should escape to another country.

A vignette is prepared for each participant, with each moral choice attribute derived from Session 1. The term moral deviant is referenced, repeatedly during the vignette induction to emphasize culpability of the 'alien other' in terms of their 'moral incapacitation'. After vignette induction, prose was presented to participants as follows:

These are questions concerning your thoughts and feelings about yourself in relation to MORAL DEVIANTS. In particular, please think about forming an ESCAPE PLAN to escape from your community and flee to safety. Please read each statement carefully and whilst IMAGINING ACTING on your ESCAPE PLAN, and decide how much the statement is generally true of you on a 1 (Not True) to 6 (Very True of Me) scale. Be sure to answer every item and try to be as honest and accurate as possible in your responses.

After induction, the Tri_P measure was subsequently readministered and participants were given the Toronto Empathy Questionnaire. Participants were asked to respond to each item, twice, for two response contexts. One response context was for "my close people", and the second was for "moral deviants".

\section{Results}

\section{Overview of analyses}

The study included a control group who were 34 participants tested, twice, on the Tri_P not less than 24 hours apart. The control group was used to confirm the temporal stability of psychopathy levels for participants not exposed to psychopathy induction. Table 1 summarizes means and standard deviations for the experimental and control group. Psychopathy levels in the control group did not vary significantly across the two times the data were sampled $(F(1,33)=0.01$, $\mathrm{p}=0.99$ ). Psychopathy levels also did not vary significantly between the control group and the experimental group, for the pre induction $(\mathrm{F}(1,66)=0.30, \mathrm{p}=0.59)$ stage of the experiment.

\begin{tabular}{|l|l|l|l|l|}
\hline \multirow{2}{*}{ Group } & \multicolumn{3}{|l|}{ Psychopathy Score (Time 1) } & \multicolumn{2}{l|}{ Psychopathy Score (Time 2) } \\
\cline { 2 - 5 } & $\mathbf{M}$ & SD & M & SD \\
\hline $\begin{array}{l}\text { Control } \\
(n=34)\end{array}$ & 139.88 & 22.48 & 140.21 & 23 \\
\hline $\begin{array}{l}\text { Test } \\
(n=34)\end{array}$ & 141.76 & 22.28 & N/A & \\
\hline
\end{tabular}

Table 1: Control group psychopathy scores.
Triarchic Psychopathy (TriP_Tot) total scores, rose significantly after psychopathy induction $(\mathrm{F}(1,31)=47.39, \mathrm{p}<0.001)$. Tables 2 summarize means and standard deviations for the psychopathy induction.

\begin{tabular}{|l|l|l|l|l|}
\hline Psychopathy Score & \multicolumn{5}{l|}{} & Post \\
\hline & Pre & SD & M & SD \\
\hline Measure & M & 22.6 & 183.1 & 34.3 \\
\hline Tri_P_Total & 141.9 & & \\
\hline N=33; ${ }^{*} p<0.001$. &
\end{tabular}

Table 2: Psychopathy levels (TriP_Total), pre- and post- psychopathy induction.

Hypotheses were tested with a 2 (Psychopathy Condition) X 2 (Empathy For) repeated measures analysis of variance experimental model, where the dependent variable was participants' empathy levels, as empathy for their Close People, before and after psychopathy induction, and empathy levels for others before (Members of the Community) and after (Moral Deviants) psychopathy induction. Participants' psychopathy levels were measured on the Triarchic Psychopathy Questionnaire (Tri_P), as per Mihailides et al. [1].

\begin{tabular}{|c|c|c|c|c|c|c|c|}
\hline \multicolumn{4}{|c|}{ Empathy For (Pre) } & \multicolumn{4}{|c|}{ Empathy For (Post) } \\
\hline \multicolumn{2}{|c|}{ My Close People } & \multicolumn{2}{|c|}{$\begin{array}{l}\text { Members of the } \\
\text { Community }\end{array}$} & \multicolumn{2}{|c|}{$\begin{array}{l}\text { My } \\
\text { People }\end{array}$} & \multicolumn{2}{|c|}{ Moral Deviants } \\
\hline M & SD & M & SD & M & SD & M & SD \\
\hline $76.6^{a}$ & 11.2 & $67.0^{\mathrm{b}}$ & 12.8 & $77.0^{\mathrm{a}}$ & 7.2 & $34.0^{c}$ & 14.7 \\
\hline
\end{tabular}

Table 3: Empathy Levels Pre and Post Psychopathy Induction by Empathy Directional Vector.

\section{Experimental analyses}

The main effect of psychopathy induction upon overall empathy levels was significant $\left(\mathrm{F}_{(1,32)}=67.90, \quad \mathrm{p}<0.001 \quad \eta^{2} \quad 2=0.68\right)$, and participants' empathy levels were significantly lower after psychopathy induction. However, the main effect was qualified by a significant univariate interaction $\left(\mathrm{F}_{(1,32)}=132.91, \quad \mathrm{p}<0.001 \quad \eta^{2} \quad 2=0.82\right)$. As suspected, there was no significant change in participants' empathy levels their Close People $\left(\mathrm{F}_{(1,32)}=2.18\right.$, ns) pre and post induction.

However, in support of hypotheses to test the Directional Vector hypothesis in relation to empathy, although participants' empathy levels for Members of the Community were significantly lower than their empathy pre-induction, for their Close People $\left(\mathrm{F}_{(1,32)}=70.57\right.$, $\mathrm{p}<0.001 \eta^{2} 2=0.63$ ), post induction, empathy levels fell for the test group.

The significant interaction indicates that participants' empathy levels post induction for Moral Deviants were significantly lower than their empathy levels, pre-induction, for Members of the Community $\left(\mathrm{F}_{(1,32)}=116.63, \mathrm{p}<0.001 \eta^{2} 2=0.79\right)$.

Results support the hypothesis that empathy is highest for one's Close Loved Ones, but lower for general Members of the Community 
Page 5 of 6

(pre-induction), and lowest for quarantined targets (Moral Deviants, post-induction). Findings are presented in Figure 1.

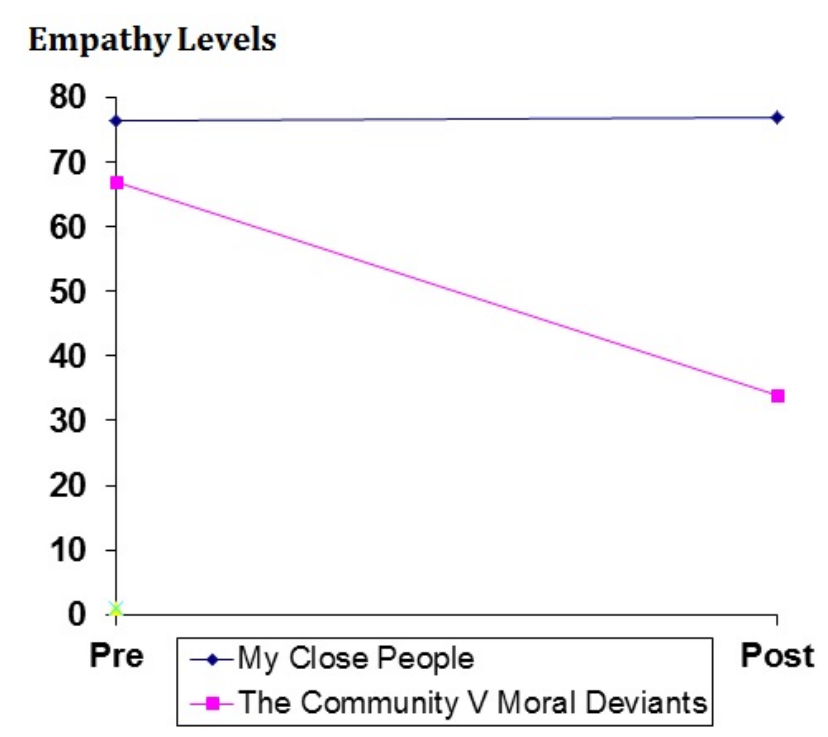

Figure 1: Effects of psychopathy induction upon participant empathy levels.

\section{Discussion}

In the current paper, the Directional Vector hypothesis was adapted to the Moral Inversion Method for a subset of socio-affective conflicts, in order to test another tenet of new theory, namely that empathy and psychopathy are not mutually exclusive, with strong support for the tenet in results. The hypothesis that empathy for one's close people should be greater than it is for members of the general community was supported. The hypothesis that empathy for members of one's own community, pre-induction, should be significantly higher than empathy for moral deviants, post psychopathy induction, was supported. Empathy levels for one's close loved ones were not significantly different pre- and post-psychopathy induction. Effect sizes (the $\eta^{2}$ statistic) indicates that they are very large. The bell curves were discriminated by over two standard deviations when comparing empathy levels for people for their close loved ones with their empathy for moral deviants.

Dual, independent processing capacities of the empathic mind and of the psychopathic modular mind were evident in findings of the study. The retained capacity to empathize with close loved ones occurred whilst diminished empathy emerged for the specific group targeted (moral deviants). Psychopathic cognition showed directional effects as did empathic cognition. Thus, the Directional Empathy hypothesis is the adjunct and subset of the overall theoretical terms we have named the Directional Vector hypothesis, of the State-Trait Psychopathy hypothesis. New theory emphasizes that extending one's empathy is an act that is independent of consideration of the conjoint act that revokes it. Said another way, a territorial incursion eliciting survival threat activates psychopathic cognition that is target group specific, and importantly, empathic cognition is quarantined from psychopathic cognition for people holding normal-range psychopathic capacity.
Mihailides et al. [1] theory posits that empathy represents one of a two-fold potential join between people. Importantly, there is facility for affect from the psychopathic spectrum to join people, by common grounding in shared psychopathic purpose. Thus, the instinct to slay, cold heartedness, baseness, cruelty, pleasure at suffering, and ghoulish humor, with directional expression, can have shared directionality for collectives. Survival threat, therefore, elicits purposeful, even predatory bearing towards particularly objectified, symbolically distinct others who are seen as holding mutually exclusive features. On the one hand, the enabling of lack of empathy for targets predicates cold, affectless decisions which would be considered amoral and in violation of dictates of socialization ordinarily [6,7,18-21]. Importantly, within this theory, affect from the psychopathic spectrum, for behaviors ordinarily in violation of the socialization contract, do not inhibit or disrupt empathy that directionally joins social collectives. Paradoxically, an empathy conjoin is thus fortified by a shared empathy disjoin where directional psychopathy (shared enemies) can have stabilizing capacity for social collectives.

Theory predicts that the strongest, clearest features that judgers identify as the 'alien, common enemy', can amplify effects of benefits of empathy for the collective that shares a common sense of territoriality. Importantly, enhanced warmth and bonding in aligned collectives is predicted, with the territorial vector of psychopathy 'binding' that subgroup. This new way of looking at alliances in collectives implies new tools for measuring new facets of mental territorial concepts. Presumably, a mental territorial annexe has areas of relative permanence versus transience. New theory suggests that collectives that share ideas about territoriality trace territorial incursion to a common alien vector. Understanding facets of the quarantined area effect can promote novel approaches to problem solving. However, implications of theory recognize that directionalities can overlap, to lesser and greater degrees in various groups and social collectives. How such multi-conflict and multi-overlap directionality can impact sociocultural development has not been developed in this work. For example, theory, thus far has not identified developmental trajectories into monolithic versus eclectic identity, nor the factors that might impact transitions between the two.

\section{Conclusions}

The Directional Vector hypothesis has been used to predict the conditions which elicit elevations in psychopathy and decrements in empathy for cognition oriented towards particular alien others. However, theory predicts a broader catchment of concepts implicated with territorial incursion and survival threat. The Directional Vector hypothesis predicts that socio-affective, socio-cultural, socio-spiritual and socio-sexual conflicts can be the basis of a targeting scanner sweeping environments, scanning for threat.

Because territoriality has emerged as central in activation of psychopathic cognition, it implicates any culturally-bound practice. Therefore, culturally bound, child-rearing practices are expected to implicate territoriality over children's safety. Because human capacity for protective care so saliently rouses strong affect about the protection of children, it is expected that human attachment behavior is deeply implicated with new ideas about vector quarantining and psychopathic cognition. It follows that the Directional Vector hypothesis can be adapted to attachment theory as well, and because the attachment literature is so prolific with a multi-decade legacy, a separate study to explore it is required. Further experimental work should be adaptable to defining how human attachment is central to territoriality and 
Citation: $\quad$ Mihailides S, Galligan R, Bates G (2017) Adaptive Psychopathy: Empathy and Psychopathy are Not Mutually Exclusive. J Foren Psy 2:

Page 6 of 6

predict how directionality in survival threat elicits psychopathic cognition.

\section{References}

1. Mihailides S, Galligan R, Bates G (2017) Reconceptualising psychopathy J Foren Psy 2.

2. Riek BM, Mania EW (2012) The antecedents and consequences of interpersonal forgiveness: A meta-analytic review. Pers. Relatsh 19: 304325.

3. Gerdes KE, Lietz CA, Segal EA (2011) Measuring empathy in the 21st century: development of an empathy index rooted in social cognitive neuroscience and social justice. Soc Work Res 35: 83-93.

4. Reniers RLEP, Corcoran R, Drake R, Shryane NM, Völlm BA (2011) The QCAE: A questionnaire of cognitive and affective empathy. J Pers Assess 93: 84-95.

5. Van Langen MAM, Wissink IB, van Vugt ES, Van der Stouwe T, Stams GJJM (2014) The relation between empathy and offending: A metaanalysis. Aggress Violent Behav 19: 179-189.

6. Gregor D, Pia H, Knut V, Andreas M, Elmar H (2012) Emotional empathy and psychopathy in offenders: An experimental study. J Pers Disord 27: 67-84.

7. Lishner DA, Vitacco MJ, Hong PY, Mosley J, Miska K, et al. (2012) Evaluating the relation between psychopathy and affective empathy: Two preliminary studies. Int J Offender Ther Comp Criminol 56: 1161-1181.

8. Tong L, Shinohara R, Sugisawa Y, Tanaka E, Yato Y, et al. (2012) Early development of empathy in toddlers: Effects of daily parent-child interaction and home-rearing environment. J Applied Social Psychol 42: 2457-2478.

9. Butrus N, Witenberg RT (2013) Some personality predictors of tolerance to human diversity: The roles of openness, agreeableness, and empathy. Aust Psychol 48: 290-298.

10. Roland K, Rideout G, Salinitri G, Frey M (2012) Development and use of a restorative justice ideology instrument: Assessing beliefs. Contemp Justice Rev 15: 435-447.

11. Brown S, Harkins L, Beech AR (2012) General and victim-specific empathy: associations with actuarial risk, treatment outcome, and sexual recidivism. Sex Abuse 24: 411-430.
12. Baron-Cohen S, Richter J, Bisarya D, Gurunathan N, Wheelright S (2003) The systemizing quotient: an investigation of adults with asperger's syndrome or highfunctioning autism, and sex differences. Philos Trans R Soc Lond B Biol Sci 358: 361-374.

13. Hare RD, Neumann CS (2010) The role of antisociality in the psychopathy construct: Comment on Skeem and Cooke (2010). Psychol Assess 22: 446-454.

14. Hare RD (2003) Manual for the hare psychopathy checklist-revised. Toronto, Canada: Multi Health Systems.

15. Lilienfeld SO, Andrews BP (1996) Development and preliminary validation of a self-report measure of psychopathic personality traits in noncriminal populations. J Pers Assess 66: 488-524.

16. Patrick CJ, Fowles DC, Krueger RF (2009) Triarchic conceptualization of psychopathy: developmental origins of disinhibition, boldness, and meanness. Dev Psychopathol 21: 913-938.

17. Blackburn $\mathrm{R}$ (1978) An empirical classification of psychopathic personality. Br J Psychiatry 127: 456-460.

18. Harpur T, Hare R, Hakstian R (1989) A two-factor conceptualization of psychopathy: construct validity and implications for assessment. Psychol Assess : J Consult Clin Psychol 103: 741-747.

19. Quay HC (1965) Psychopathic personality and pathological sensation seeking. Am J Psychiatry 122: 180-183.

20. Quay HC (1977) Psychopathic behaviour: Reflections on its nature origins and treatment. The structuring of experience :155-171

21. Zuckerman M (1991) Psychobiology of Personality. Cambridge University press.

22. Marsh AA, Cardinale EM (2012) Psychopathy and fear: Specific impairments in judging behavior that frightens others. Emotion 12: 892-898.

23. Bird G, Viding E (2014) The self to other model of empathy: Providing a new framework for understanding empathy impairments in psychopathy, autism, and alexithymia. Neurosci Biobehav Rev 47: 520-532.

24. Singer T, Lamm C (2009) The social neuroscience of empathy. Ann NY Acad Sci 1156: 81-96. 